\title{
Defensive properties of secondary metabolites from the Caribbean gorgonian coral Erythropodium caribaeorum
}

\author{
William Fenical ${ }^{1}$, Joseph R. Pawlik ${ }^{2}$ \\ ${ }^{1}$ University of California, San Diego, Scripps Institution of Oceanography, La Jolla, California 92093-0236, USA \\ ${ }^{2}$ Department of Biological Sciences and Center for Marine Science Research, University of North Carolina at Wilmington, \\ Wilmington, North Carolina 28403-3297, USA
}

\begin{abstract}
Field experiments support previous laboratory assays indicating that crude lipid-soluble extracts of the Caribbean encrusting gorgonian octocoral Erythropodium caribaeorum (Duchassaing \& Michelotti) deter predation by reef fishes. An extract of E. caribaeorum incorporated into carrageenan food strips at the same volumetric concentration as it occurred in gorgonian tissues deterred feeding of a natural assemblage of fishes on the same reef from which the gorgonian had been collected. Field assays using carrageenan strips containing naturally occurring concentrations of several purified secondary metabolites isolated from the crude extract revealed that the feeding deterrent effects were present in a fraction containing chlorinated diterpenoid $\left(C_{20}\right)$ compounds (erythrolides), but not in a fraction containing sesquiterpene $\left(C_{15}\right)$ hydrocarbons (of which erythrodiene, a previously unreported marine natural product, was a major component). Three compounds were purified from the erythrolide fraction: erythrolide $\mathrm{A}$, erythrolide $\mathrm{B}$ and erythrolide D. Only the last 2 of these compounds, when assayed independently, inhibited feeding of reef fishes at the natural concentrations found in $E$. caribaeorum. While the erythrolides appear to defend $E$. caribaeorum from reef predators, the function of sesquiterpene hydrocarbons, which occur in high concentrations in the lipid-soluble extracts of many octocorals, remains unclear.
\end{abstract}

\section{INTRODUCTION}

Gorgonian corals are found in all tropical and subtropical seas, but reach their greatest levels of diversity and abundance on Caribbean coral reefs (Bayer 1961, Kinzie 1973), where they attain densities as high as 25 colonies $\mathrm{m}^{-2}$ (Goldberg 1973). Unlike scleractinian corals, which have only a thin veneer of living tissue on an endoskeleton of rock-hard carbonate, gorgonians possess a relatively fleshy coenenchyme that usually surrounds a supportive rod or mesh of sclerotinized protein. Given the nutrient scarcity and high levels of predation reported for coral reef environments (Grigg et al. 1984, Huston 1985), it might be expected that gorgonians would provide a source of food for a variety of reef predators, but this does not appear to be the case (Pawlik et al. 1987).

Only a few species have been observed to prey on Caribbean gorgonians: the butterflyfish Chaetodon capistratus, which feeds on extended polyps in some localities (Lasker 1985), the amphinomid polychaete
Hermodice carunculata, a predator on a wide variety of coral reef cnidarians (Vreeland \& Lasker 1989), and ovulid molluscs, most notably Cyphoma gibbosum. which graze specifically on gorgonian tissues (Gerhart 1986, Harvell \& Suchanek 1987, Lasker \& Coffroth 1988). Additionally, it has been noted that these few predators are highly selective in their choice of prey species (Vreeland \& Lasker 1989).

Chemical defense has been the primary explanation for the relative lack of predation on gorgonian corals. Natural products chemists have isolated over 200 novel secondary metabolites from these animals (Fenical 1982, Faulkner 1990 and previous reviews by the same author); some of these compounds occur at extraordinarily high concentrations within the coral tissues (Schneider et al. 1977). Although pharmacological effects of many of these compounds have been described (see references in Pawlik et al. 1987), only recently have the possible functions of these metabolites in gorgonians been addressed by employing ecologically relevant laboratory and field experiments 
(Gerhart 1984, Pawlik et al. 1987, Harvell et al. 1988 Harvell \& Fenical 1989, Pawlik \& Fenical 1989).

In a previous investigation, we surveyed the feeding deterrence of lipid-soluble extracts of 37 types of Caribbean gorgonians by employing a common predatory Caribbean reef fish, Thalassoma bifasciatum, in shipboard aquarium assays (Pawlik et al. 1987). In those experiments, 2 species, Pseudopterogorgia rigida and Erythropodium caribaeorum, deterred fish feeding at food pellet concentrations less than an order of magnitude lower than those found in the gorgonian soft tissues. These observations prompted subsequent indepth studies on the chemical defenses of $P$. rigida (Harvell et al. 1988, Harvell \& Fenical 1989), and, in the present case, of E. caribaeorum.

Erythropodium caribaeorum is an unusual gorgonian in that it grows over the substrate as an encrusting sheet rather than upright on an axial skeleton. It is a dominant component of the gorgonian fauna in many localities (e.g. Jamaica: Kinzie 1973; Florida: Goldberg 1973. Opresko 1973). The species is particularly common in back reef areas and in fore reef zones dominated by fragile scleractinian corals such as Acropora cervicornis and Madracis mirabilis, where, by virtue of an unusual growth form, E. caribaeorum persists on unstable substrates (Kinzie 1973). In Acropora cervicornis zones on Jamaican reefs, Kinzie (1973) reported that $90 \%$ of the gorgonian biomass was made up of $E$. caribaeorum and a second species with an encrusting form, Briareum asbestinum. In Floridian waters, E. caribaeorum is prevalent on patch reefs (Goldberg 1973); on one such reef, it was the fourth most abundant, making up $12 \%$ of the gorgonians present (Opresko 1973).

An earlier research program involved with the characterization of biologically active compounds from Caribbean gorgonians resulted in the purification of structurally undefined sesquiterpene hydrocarbons (Look 1983) and several chlorinated diterpenoids (Look et al. 1984) from Erythropodium caribaeorum. The purpose of the present study was to extend our preliminary investigation (Pawlik et al. 1987) by isolating and identifying the specific components of E. caribaeorum responsible for chemical defense. An emphasis was placed on the purification, identification and deterrence-testing of the sesquiterpene hydrocarbon fraction, because these compounds are particularly abundant in gorgonian corals and their function is unknown.

\section{MATERIALS AND METHODS}

Gorgonian collection. Most of this study was completed during an expedition to the reefs surrounding the Bahama Islands on board the research vessel
'Columbus Iselin' in June 1989. Erythropodium caribaeorum was collected by SCUBA at 3 to $25 \mathrm{~m}$ depth from Chub Cay ( 3 collections) and San Salvador ( 1 collection), Bahamas. Previously, a collection of $E$. caribaeorum had been obtained from Cane Bay, St. Croix, U.S. Virgin Islands, in January 1989. Collections were made of single colonies in order to assess intraspecific variation of secondary metabolite composition. The encrusting gorgonians were scraped off coral rubble, brought on board ship and air-dried for ca 2 to $4 \mathrm{~h}$. Possible degradation of the secondary metabolites found in tissues of E. caribaeorum had been explored previously and the compounds were known to be stable (Look et al. 1984). A small subsample of the first collection was extracted for field assays; all other samples were frozen for later laboratory analyses.

Extraction and isolation. The volume of the small subsample of Erythropodium caribaeorum was determined by displacement of a known volume of dichloromethane $\left(\mathrm{CH}_{2} \mathrm{Cl}_{2}\right)$ in a graduated cylinder. The subsample was macerated in a blender and fully extracted with the same solvent. Dichloromethane was used as the extraction solvent because earlier studies showed it effectively extracted the deterrent compounds. The resulting extract was divided into 4 equal aliquots dissolved in minimal amounts of diethyl ether and kept at $-20^{\circ} \mathrm{C}$ until used. Two of the aliquots were used in field assays of the crude extracts of $E$. caribaeorum. The other 2 aliquots were combined and the secondary metabolites isolated by vacuum flash chromatography on silica gel employing a 10 to $50 \%$ ethyl acetate in isooctane gradient. Isolation procedures were monitored by employing silica gel thinlayer chromatography (TLC) on Merck plastic-backed plates impregnated with fluorescent indicator and developed by heating after misting with a solution of $50 \%$ concentrated sulfuric acid in water. The least polar fractions yielded a mixture of hydrocarbons, which were combined into a single fraction. Half of the hydrocarbon fraction was assayed (below) and the other half retained for laboratory analysis. The more polar fractions yielded a mixture of erythrolide diterpenoids and typical sterols. These were also combined into a single fraction, divided into 2 aliquots, and one aliquot was assayed. The other aliquat was further separated by silica gel high-performance liquid chromatography (HPLC) on a preparative column with $50 \%$ ethyl acetate in isooctane as the eluant. This procedure yielded 3 pure compounds and an HPLCinseparable mixture of monohydroxysterols. Each of the 3 compounds and the sterol mixture were assayed.

Quantitative analysis of gorgonian samples was performed at Scripps Institution of Oceanography. Frozen samples, including a subsample from the same gorgonian colony used in field assays, were thawed, wet and 
dry weights determined, and extracted as before. The same isolation procedures were performed as on-board ship, the HPLC fractions were weighed, and the compounds were identified by ${ }^{1} \mathrm{H}$ and ${ }^{13} \mathrm{C}-\mathrm{NMR}$ spectrometric methods. Erythrolides A and B were unambiguously identified by comparison with purified standards. Erythrolide D was identified by spectral methods (Pordesimo et al. 1991) and by an X-ray crystallographic investigation. Purification of the hydrocarbon fraction by HPLC (100\% isooctane on silica) led to the isolation of a single, previously unknown, spirobicyclic sesquiterpene, erythrodiene, which was identified by spectral, chemical and X-ray crystallographic methods (Fenical unpubl. results).

Field assays. Extracts and fractions isolated from extracts of Erythropodium caribaeorum were volumetrically reconstituted in a matrix of carrageenan at the same concentrations as they occurred in the gorgonian; strips of this matrix were then used in field experiments (see methods in Harvell \& Fenical 1989, Pawlik \& Fenical 1989). The matrix was made by combining 3 to 4 g carrageenan (Gelcarin, FF961L; FMC Corp, PA, USA) and ca $20 \mathrm{ml}$ of tuna fish puree (tuna packed in oil, pureed in a minimal volume of deionized water in a blender) with deionized water to a total volume of $60 \mathrm{ml}$. The mixture was heated to boiling in a microwave oven (about 1 min on 'cook'), then the extract in a minimal volume of solvent (treated matrix), or solvent alone (control matrix), was added. The mixture was stirred and heated again to boiling (extracts were previously judged to be stable to this treatment). The molten mixture was then poured into plastic molds crossed by lengths of cotton string that protruded from the ends of the molds. After the matrix cooled and gelled, $1.0 \times 0.5 \times 5.0 \mathrm{~cm}$ strips were sliced to size with a scalpel and removed from the mold. For each experiment, 20 treated strips and 20 control strips were prepared. To distinguish treated from control strips, the cotton string attached to each strip was marked with a small colored ink spot.

Field assay methods were based on those of Hay (1984) as modified by Pawlik \& Fenical (1989). One treatment and one control strip each were tied to a 50 $\mathrm{cm}$ length of 3 -strand nylon rope at a distance of ca 4 and $12 \mathrm{~cm}$ from one end of the rope (the order was haphazard). Twenty ropes were deployed on the reef for each experiment, with the end of each rope opposite the food strips unwound and clamped onto a piece of coral or rock. All experiments were performed at 8 to 10 m water depth off Mama Rhoda Rock, Chub Cay, Bahamas. Identifications of fishes sampling food strips were made by consulting Randall (1983). Within $1 \mathrm{~h}$, the ropes were retrieved and the amount of each strip eaten was recorded as a percentage decrease in the strip length (to the nearest $5 \%$ ). The Wilcoxon paired- sample test (1-tailed; Zar 1984) was employed to analyse the results after excluding pairs for which both control and treatment slices had been either completely eaten, or not eaten at all.

Laboratory assays. In preliminary experiments with specialist predators on gorgonians, one of each assay strip containing a volumetrically equivalent amount of a crude dichloromethane extract of the gorgonian Pseudopterogorgia americana (control) and extracts of both P. americana and Erythropodium caribaeorum (treatment) were placed in plastic enclosures (approximately cubical, $12 \mathrm{~cm}$ on a side, with mesh windows on 3 of 6 sides) containing either 3 specimens of the snail Cyphoma gibbosum (10 replicates) or 2 specimens of the polychaete Hermodice carunculata (6 replicates). Enclosures were kept in laboratory aquaria supplied with flowing seawater for $48 \mathrm{~h}$ prior to examination of the assay strips.

\section{RESULTS}

Assay strips containing a crude dichloromethane extract of Erythropodium caribaeorum at the same volumetric concentration as the extract occurs in the gorgonian significantly deterred feeding of a natural assemblage of reef fishes $(p<0.0005$, Wilcoxon pairedsample test; Fig. 1). Food strips set out on the reef for

\section{CRUDE EXTRACT; $N=18(17), P<0.0005$}

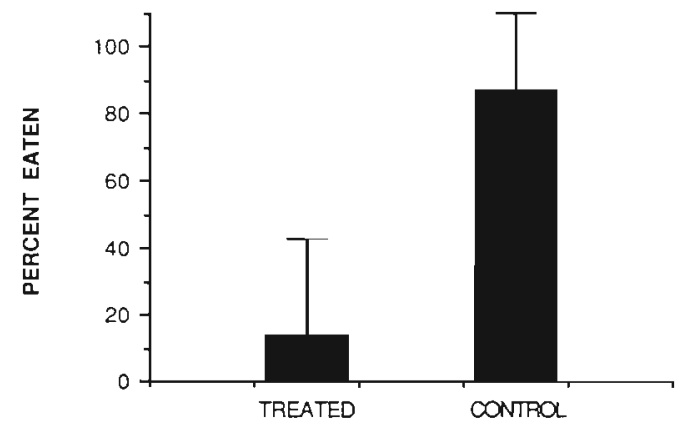

Fig. 1. Consumption by reef fishes of paired control food strips and strips containing a crude extract of Erythropodium caribaeorum at the same concentration as is found in the tissues of the gorgonian. Vertical lines through each histogram indicate one standard deviation above the mean. $\mathrm{N}=$ no. of paired treatment and control strips retrieved of 20 deployed (no. of pairs used in statistical analysis). Probability calculated using the Wilcoxon paired-sample test

this and subsequent assays were primarily sampled by yellowtail snapper Ocyurus chrysurus and bluehead wrasse Thalassoma bifasciatum. Occasionally, small parrotfish Scarus iserti were observed biting strips.

In laboratory assays, specimens of the ovuliid snail Cyphoma gibbosum were observed to graze control assay strips containing a crude extract of Pseudoptero- 
gorgia americana, but not treatment strips containing extracts of both $P$. americana and Erythropodium caribaeorum. In addition, snails feeding on control assay strips made fecal pellets of the same color as the food strips. Unfortunately, snails grazed only a thin veneer off the surface of the food strips, so the amount they consumed could not be quantified. Moreover, the food strips began to decompose after $2 \mathrm{~d}$ and the experiments were subsequently ended. Specimens of the polychaete Hermodice carunculata appeared to have fed indiscriminately on control and treatment food strips, but again, the strips began to decompose after $2 \mathrm{~d}$ making quantification impossible.

Flash chromatographic separation of the crude extract of Erythropodium caribaeorum yielded 2 fractions containing secondary metabolites: the hydrocarbon fraction and the erythrolide fraction. The other lipid-soluble components of the crude extract were primary metabolites (fats and sterols). The hydrocarbon fraction did not significantly deter consumption of treated assay strips by reef fishes (Fig, 2A). HPLC analysis revealed that the hydrocarbon fraction was

A HYDROCARBON FRACTION; $N=20(13), P>0.25$

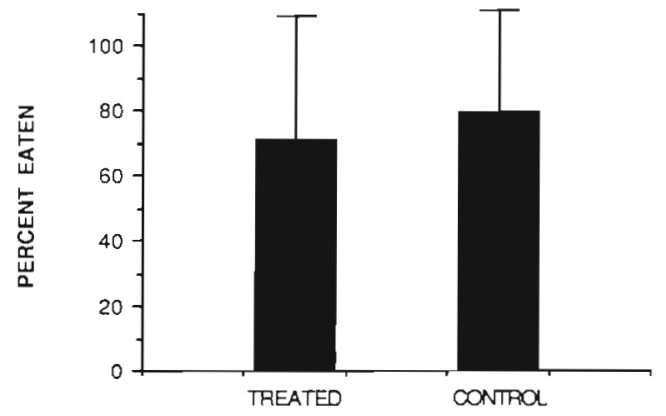

B ERYTHROLIDE FRACTION; $N=20(18), P<0.0005$

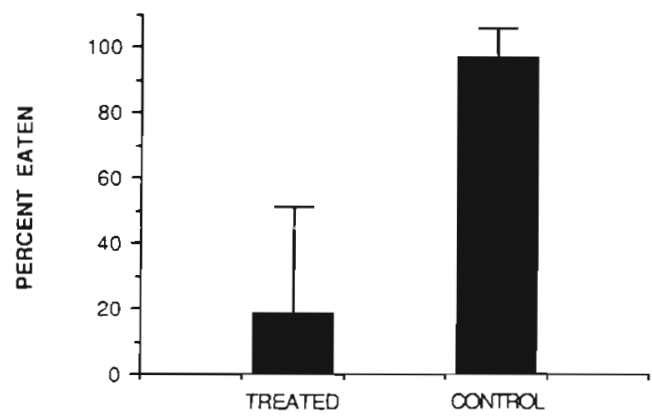

Fig. 2. Consumption by reef fishes of palred control food strips and strips containing natural concentrations of $(A)$ the hydrocarbon fraction and (B) the erythrolide-containing fraction isolated from the crude extract of Erythropodium caribaeorum. Vertical lines through each histogram indicate one standard deviation above the mean. $\mathrm{N}=$ no. of paired treatment and control strips retrieved of 20 deployed (no. of pairs used in statistical analysis). Probabilities calculated using the Wilcoxon paired-sample test composed of saturated linear hydrocarbons and a new bicyclic spirosesquiterpene, erythrodiene (Fig. 3). Erythrodiene, which constituted $69 \%$ of the hydrocarbon fraction, is a terpene hydrocarbon of a rare class and its presence in $E$. caribaeorum has not been reported previously The structural determination of erythrodiene was ultimately accomplished by X-ray analysis of a suitable derivative (Fenical unpubl. results).

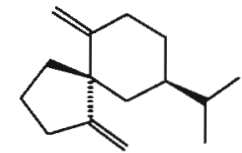

Erythrodiene $69 \% \mathrm{HC}$ fraction

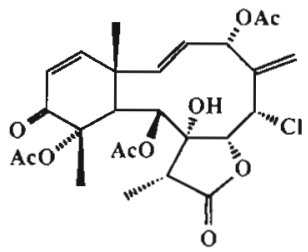

Erythrolide B

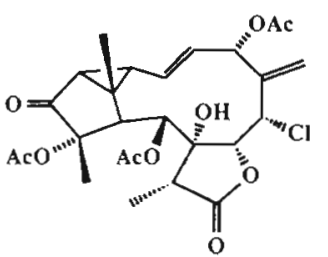

Erythrolide A
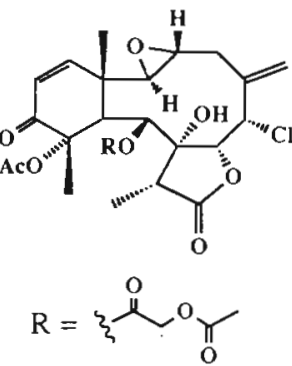

Erythrolide D
Fig. 3. Compounds purified from extracts of Erythropodium caribaeorum and used in field assays

The erythrolide fraction deterred feeding at concentrations that occur naturally in the tissues of Erythropodium caribaeorum (Fig. 2B). Fractionation of the extract by HPLC yielded 3 pure compounds, erythrolides A, B, and D (Fig. 3), and one homogeneous mixture (i.e. 1 peak on HPLC) of mono-hydroxysterols. Of these, only erythrolides B and D inhibited fish feeding in field assays (Fig. 4). The relative percentages of these compounds (brr HPLC analysis) in extracts of 5 collections of $E$. caribaeorum, including a subsample from the collection used in field assays, is shown in Table 1.

\section{DISCUSSION}

Previously, we demonstrated that a crude, dichloromethane extract of Erythropodium caribaeorum applied to food pellets at a range of concentrations (0.09 to $6.3 \%$ dry weight) inhibited the feeding of the Caribbean reef fish Thalassoma bifasciatum in laboratory aquaria (Pawlik et al. 1987). The present study 
A

STEROLS; $N=20(13), P=0.25$

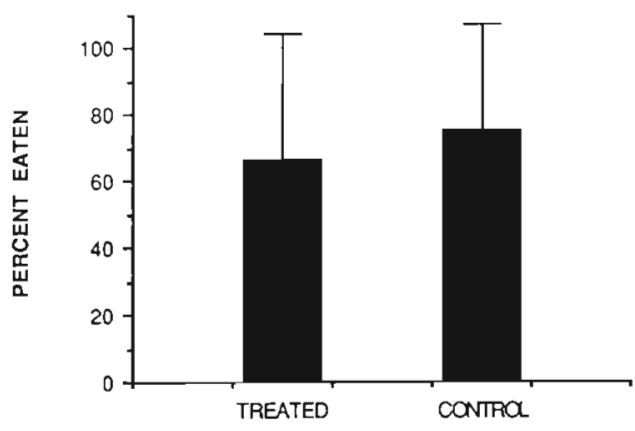

C

ERY. D; $N=19(15), P<0.025$

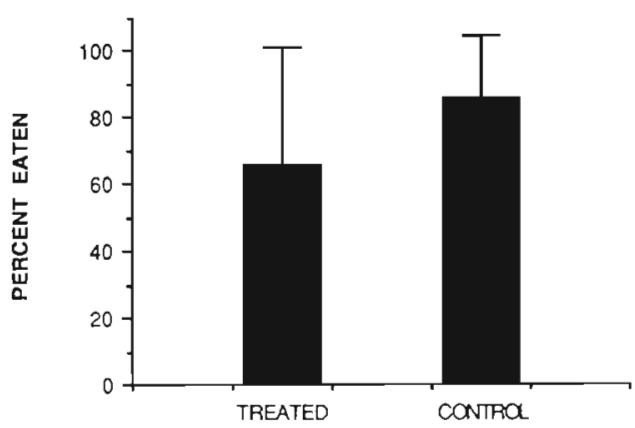

B

ERY. B: $N=20(16), P<0.0025$

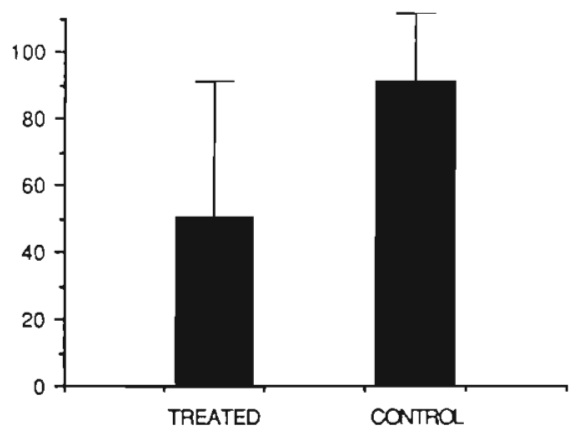

ERY. $A ; \quad N=20(17), P>0.25$

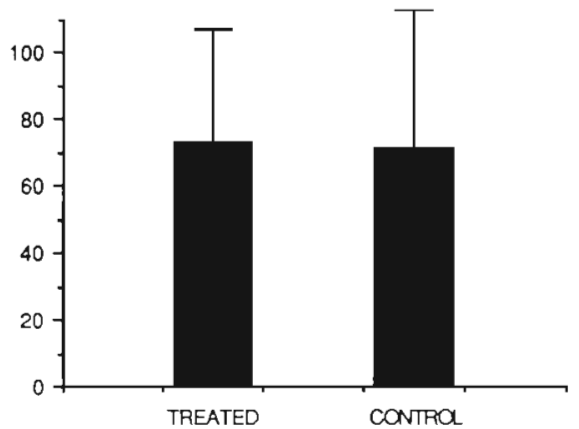

Fig. 4. Consumption by reef fishes of paired control food strips and strips containing natural concentrations of a sterol mixture and of 3 purified compounds. (A) Sterols; (B) erythrolide B; (C) erythrolide D; (D) erythrolide A. Vertical lines through each histogram indicate one standard deviation above the mean. $N=$ number of paired treatment and control strips retrieved of 20 deployed (number of pairs used in statistical analysis). Probabilities calculated using the Wilcoxon paired-sample test

Table 1. Results of analyses of lipid-soluble extracts of Erythropodium caribaeorum from 5 samples. Ery. A etc.. erythrolide A etc.

\begin{tabular}{|c|c|c|c|c|c|c|c|c|}
\hline \multirow[t]{2}{*}{ Sample } & \multirow{2}{*}{$\begin{array}{l}\text { Date } \\
(1989)\end{array}$} & \multirow[t]{2}{*}{ Location } & \multicolumn{6}{|c|}{ Percentage dry weight } \\
\hline & & & Extract & Hydrocarbons & Sterols & Ery. A & Ery, B & Ery. D \\
\hline $1^{\mathrm{d}}$ & 8 Jun & $\begin{array}{l}\text { Chub Cay, } \\
\text { Bahamas, } 3 \text { m }\end{array}$ & 4.3 & - & 0.30 & 0.52 & 0.52 & 0.17 \\
\hline 2 & 8 Jun & $\begin{array}{l}\text { Chub Cay, } \\
\text { Bahamas, } 5 \mathrm{~m}\end{array}$ & 3.8 & - & 0.30 & 0.30 & 0.72 & 0.42 \\
\hline 3 & 9 Jun & $\begin{array}{l}\text { Chub Cay, } \\
\text { Bahamas, } 15 \mathrm{~m}\end{array}$ & 3.4 & 0.20 & 0.31 & 0.51 & 0.48 & 0.20 \\
\hline 4 & 20 Jun & $\begin{array}{l}\text { San Salvador, } \\
\text { Bahamas, } 23 \mathrm{~m}\end{array}$ & 3.8 & - & 0.30 & 0.53 & 0.34 & 0.53 \\
\hline \multirow[t]{3}{*}{5} & $22 \mathrm{Jan}$ & $\begin{array}{l}\text { St. Croix, } \\
\text { U.S.V.I., } 18 \mathrm{~m}\end{array}$ & $--^{b}$ & - & 0.29 & 0.34 & 0.53 & 0.29 \\
\hline & & Mean & 3.8 & - & 0.30 & 0.44 & 0.52 & 0.32 \\
\hline & & $\mathrm{SD}$ & 0.4 & - & 0.01 & 0.11 & 0.14 & 0.15 \\
\hline $\begin{array}{l}\text { a Sample } \\
\text { b \% dry } \\
\text {-: not de }\end{array}$ & $\begin{array}{l}\mathrm{d} \text { in fiel } \\
\text { hht of co } \\
\text { ined }\end{array}$ & ays & mes the & erage $\%$ dry & hit of e & $s$ for $S a$ & 1 to 4 & \\
\hline
\end{tabular}

extends our preliminary findings by demonstrating that a crude extract of $E$. caribaeorum incorporated into a carrageenan matrix at the same concentration present in the gorgonian deterred the feeding of a natural assemblage of reef fishes (Fig. 1). Moreover, erythrolides $\mathrm{B}$ and $\mathrm{D}$ (Fig. 3) appear to be responsible for the 
defensive properties, while the other metabolites in the extract, particularly the hydrocarbons and sterols, were not deterrent at natural concentrations (dry weight concentrations are presented in Table 1 for comparison). While erythrolides B and D were both effective feeding deterrents independently, it is likely that their combined occurrence in gorgonian tissue has a cumulative or synergistic effect, as evidenced by the strong deterrent activity of the erythrolide fraction containing both compounds (Fig. 2B).

Although our preliminary survey indicated that chemical defense may play an important role in the ecology of Caribbean gorgonians (Pawlik et al. 1987), a direct link between specific secondary metabolites and feeding deterrence has been demonstrated in only one species besides Erythropodium caribaeorum: Harvell et al. (1988) found that curcuhydroquinone and curcuquinone from Pseudopterogorgia rigida inhibited feeding in field assays. The high concentrations of prostaglandins present in some gorgonians of the genus Plexaura, particularly Plexaura homomalla, had previously been thought to play an ichthyodeterrent role (Gerhart 1984), but subsequent assays of the derivatives of these compounds as they occur naturally in the gorgonian tissues indicated that most were inactive (Pawlik \& Fenical 1989). Among octocorals in general, a purified cembranoid diterpene from the Indo-Pacific alcyonacean Sinularia maxima inhibited the feeding of fishes when assayed at natural concentrations on reefs in Guam (Wylie \& Paul 1989).

The concentrations of extracts, fractions, and pure compounds used in this study approximated those found occurring in the tissues of Erythropodium caribaeorum. Concentrations of the secondary metabolites in the sample used for the assay were at or below mean levels for 5 samples of E. caribaeorum from 3 Caribbean localities (Table 1). The volumetric method employed in this study (first described by Harvell et al. 1988) proved particularly useful on-board ship, where gravimetric analyses were not feasible. Any error in our volumetric reconstitution of the carrageenan matrix to match the naturally occurring concentration of secondary metabolites in E. caribaeorum would have been conservative, i.e. assay concentrations would have tended to be lower than natural concentrations, because the volume occupied by calcitic sclerites in the tissues of the gorgonian was not taken into account, nor was the loss of metabolites with each chromatographic step. Also, secondary metabolites may be concentrated in the gorgonian tissues most likely to be attacked by predatory fishes; e.g. Harvell \& Fenical (1989) have demonstrated that curcuhydroquinone is concentrated in the polyps of Pseudopterogorgia rigida. In the assay procedure used here, compounds were distributed homogeneously throughout the carrageenan matrix of the food strips. It is not known whether secondary metabolites are heterogeneously distributed in E caribaeorum.

The organic extracts of marine octocorals are characteristically rich in sesquiterpene hydrocarbons (Tursch et al. 1978). Although no function had been empirically demonstrated for these compounds, they had been presumed to function as defensive metabolites. Available evidence indicates that this may not be true. The hydrocarbon fraction assayed in this study was not deterrent (Fig. 2A). Similarly, a mixture of hydrocarbons from extracts of Pseudopterogorgia rigida containing mostly the sesquiterpene curcumene was not deterrent (Harvell et al. 1988), nor did a terpene hydrocarbon fraction isolated from 3 Sinularia species inhibit the feeding activity of the butterflyfish Chaetodon unimaculatus (Wylie \& Paul 1989).

Results of this study raise an interesting question regarding the relationship between compound structure and feeding-deterrent activity. Erythrolides A and $B$ were assayed at the same concentrations, yet only the latter was an effective deterrent. These 2 compounds are chemically related, but they possess different carbon skeletons. This difference could account for their varying bioactivities. It has been shown previously that erythrolide $\mathrm{B}$ can be converted to erythrolide $\mathrm{A}$ by a photochemical process (Look et al. 1984). Therefore, it is not known whether erythrolide $A$ is a biosynthetic product or simply an artifact produced by the natural exposure of coral tissue to sunlight.

Although secondary metabolites appear to protect Erythropodium caribaeorum from reef fishes, the deterrent effects of these compounds on invertebrate predators has not been rigorously assessed. As an alternative, secondary metabolites may stimulate feeding by specialized gorgonian predators. The snail Cyphoma gibbosum, a specialist predator on gorgonians, consumed food strips laced with an extract of Pseudopterogorgia americana, a gorgonian it readily eats in the field, but did not eat strips laced with extracts of both $P$. americana and E. caribaeorum, the latter of which it has not been observed to graze (C. D. Harvell pers. comm.). Whether the same metabolites from $E$. caribaeorum that deter feeding of reef fishes deter grazing by $C$. gibbosum remains unknown. Our preliminary observations suggest that the amphinomid polychaete Hermodice carunculata is not deterred by extracts of $E$. caribaeorum, although confirmatory experiments would be required to validate this finding. Vreeland \& Lasker (1989) have examined feeding preferences of these worms on Panamanian and Puerto Rican reefs, but $E$. caribaeorum does not occur there. The prostrate growth form of E. caribaeorum, combined with its tendency to grow on coral rubble, would make it particularly susceptible to predation by $H$. 
carunculata. This encrusting form of growth may also make $E$. caribaeorum more likely to be overgrown by scleractinian corals, other invertebrates, or algae, or to be fouled by their propagules; secondary metabolites may deter organisms that compete with E. caribaeorum for space.

The role of calcitic sclerites in the coenenchyme of Erythropodium caribaeorum as a physical defense against predation was not examined in this study. These spicules make up ca $90 \%$ of the ash-free dry weight of the coenenchyme of E. caribaeorum. Harvell et al. (1988) demonstrated that the addition of sclerites from Pseudopterogorgia acerosa to carrageenan food strips deterred feeding by reef fish in field assays. However, as they pointed out, Caribbean reef fish generally consume the extended polyps of gorgonians, which are free of sclerites, rather than the coenenchyme (Harvell \& Fenical 1989 and references cited therein). Sclerites may defend gorgonians from some invertebrate predators that eat the coenenchyme (Harvell \& Fenical 1989), but available evidence indicates that this is not the case for the mollusc Cyphoma gibbosum (Harvell \& Suchanek 1987), or the polychaete Hermodice carunculata (Vreeland \& Lasker 1989). In Guam, Wylie \& Paul (1989) found that butterflyfishes preferred to feed on the coenenchyme of species of Sinularia that had the greatest concentrations of large, sharp sclerites, but avoided species with small, powdery sclerites. For octocorals, chemical rather than structural defenses may play the larger role in predator deterrence.

Acknowledgements. This research, and the use of the research vessel 'Columbus Iselin', was supported by grants from the National Science Foundation, Chemistry and Oceanography Divisions (CHE86-20217 and CHE90-08621 to W.F.). Financial support was partially provided to J.R.P. by a Killam Memorial Postdoctoral Fellowship awarded through the University of Alberta, Edmonton, Canada. We are grateful to D. Harvell, M. Hay, J. Porta, V. Roussis, A Sewell, K. Van Alstyne and the captain and crew of RV 'Columbus Iselin' for their assistance and cooperation in performing this research. Ash-free dry weight analyses were provided by C. D. Harvell. We thank the government of the Bahamas for permission to perform research in their territorial waters.

\section{LITERATURE CITED}

Bayer, F. M. (1961). The shallow-water octocorallia of the West Indian region. Martinus Nijhoff, The Hague

Faulkner, D, J. (1990). Marine natural products. Nat. Prod. Rep. 7: 269-309

Fenical, W. (1982). Natural products chemistry in the marine environment. Science 215: 923-928

Gerhart, D. J. (1984). Prostaglandin $A_{2}$ : an agent of chemical defense in the Caribbean gorgonian Plexaura homomalla. Mar. Ecol. Prog. Ser. 19: 181-187

Gerhart, D. J. (1986). Greqariousness in the gorgonian-eating gastropod Cyphoma gibbosum: tests of several possible causes. Mar Ecol. Prog. Ser. 31: 255-263

Goldberg, W M. (1973). The ecology of the coral-octocoral communities off the Southeast Florida coast: geomorphology, species composition, and zonation. Bull. mar. Sci. 23: $465-488$

Grigg, R. W., Polovina, J. J., Atkinson, M. J. (1984). Model of a coral reef ecosystem. III. Resource limitation, community regulation, fisheries yield and resource management. Coral Reefs 3: 23-27

Harvell, C. D., Fenical, W. (1989). Chemical and structural defenses of Caribbean gorgonians (Pseudopterogorgia spp.): intracolony localization of defense. Limnol. Oceanogr. 34: 382-389

Harvell, C. D., Fenical, W., Greene, C. H. (1988). Chemical and structural defenses of Caribbean gorgonians (Pseudopterogorgia spp.). I. Development of an in situ feeding assay. Mar Ecol. Prog. Ser. 49: 287-294

Harvell, C. D., Suchanek, T H. (1987). Partial predation on tropical gorgonians by Cyphoma gibbosum (Gastropoda). Mar. Ecol. Prog. Ser. 38: 37-44

Hay, M. E. (1984). Patterns of fish and urchin grazing on Caribbean coral reefs: are previous results typical? Ecology 65: 446-454

Huston, M. A. (1985). Patterns of species diversity on coral reefs. Ann. Rev. Ecol. Syst. 16: 149-177

Kinzie, R. A. (1973). The zonation of West Indian gorgonians. Bull. mar. Sci. 23: 93-155

Lasker, H. R. (1985). Prey preferences and browsing pressure of the butterflyfish Chaetodon capistratus on Caribbean gorgonians. Mar Ecol. Prog. Ser. 21: 213-220

Lasker, H. R., Coffroth, M. A. (1988). Temporal and spatial variability among grazers: variability in the distribution of the gastropod Cyphoma gibbosum on octocorals. Mar. Ecol. Prog. Ser. 43: 285-295

Look, S. A. (1983). Studies of the natural products chemistry of selected Caribbean gorgonians. Ph.D. dissertation, University of California, San Diego

Look, S. A., Fenical, W., Van Engen, D., Clardy, J. (1984). Erythrolides: unique marine diterpenoids interrelated by a naturally occurring di-pi-methane rearrangement. J. Am. Chem. Soc. 106: 5026-5027

Opresko, D. M. (1973). Abundance and distribution of shallow-water gorgonians in the area of Miami, Florida. Bull. mar. Sci. 23: 535-558

Pawlik, J. R., Burch, M. T., Fenical, W. (1987), Patterns of chemical defense among Caribbean gorgonian corals: a preliminary survey. J. exp mar Biol. Ecol. 108: 55-66

Pawlik, J. R., Fenical, W. (1989). A re-evaluation of the ichthyodeterrent role of prostaglandins in the Caribbean gorgonian coral Plexaura homomalla. Mar. Ecol. Prog. Ser. 52: $95-98$

Pordesimo, E. O., Schmitz, F. J., Ciereszki, L. S., Hossain, M. B., Van der Helm, D. (1991). New briareum diterpenes from the Caribbean gorgonians Erythropodium caribaeorum and Briareum sp. J. org. Chem. 56: 2344-2357

Randall, J. E. (1983). Caribbean reef fishes, 2nd edn., revised. TFH Publications, Neptune City

Schneider, W. P., Bundy, G. L., Lincoln, F. H., Daniels, E. G., Pike, J. E. (1977). Isolation and chemical conversions of prostaglandins from Plexaura homomalla: preparation of prostaglandin $E_{2}$, prostaglandin $F_{2}$ and their 5,6-trans isomers. J. Am. Chem. Soc. 99: 1222-1232

Tursch, B., Braekman, J. C., Daloze, D., Kaisin, M. (1978). Terpenoids from colelenterates. In: Scheuer, P. J. (ed.) Marine natural products, chemical and biological perspectives. Academic Press, New York, p. 247-296 
Vreeland, H. V., Lasker, H. R. (1989). Selective feeding of the polychaete Hermodice carunculata Pallas on Caribbean gorgonians. J. exp. mar. Biol. Ecol. 129: 265-277

Wylie, C. R., Paul, V J. (1989). Chemical defenses in three species of Sinularia (Coelenterata, Alcyonacea): effects

This article was submitted to the editor against generalist predators and the butterflyfish Chaetodon unimaculatus Bloch. J. exp. mar. Biol. Ecol. 129; $141-160$

Zar, J. H. (1984). Biostatistical analysis, 2nd edn. PrenticeHall, Englewood Cliffs

Manuscript first received: February 21, 1991

Revised version accepted: May 24, 1991 